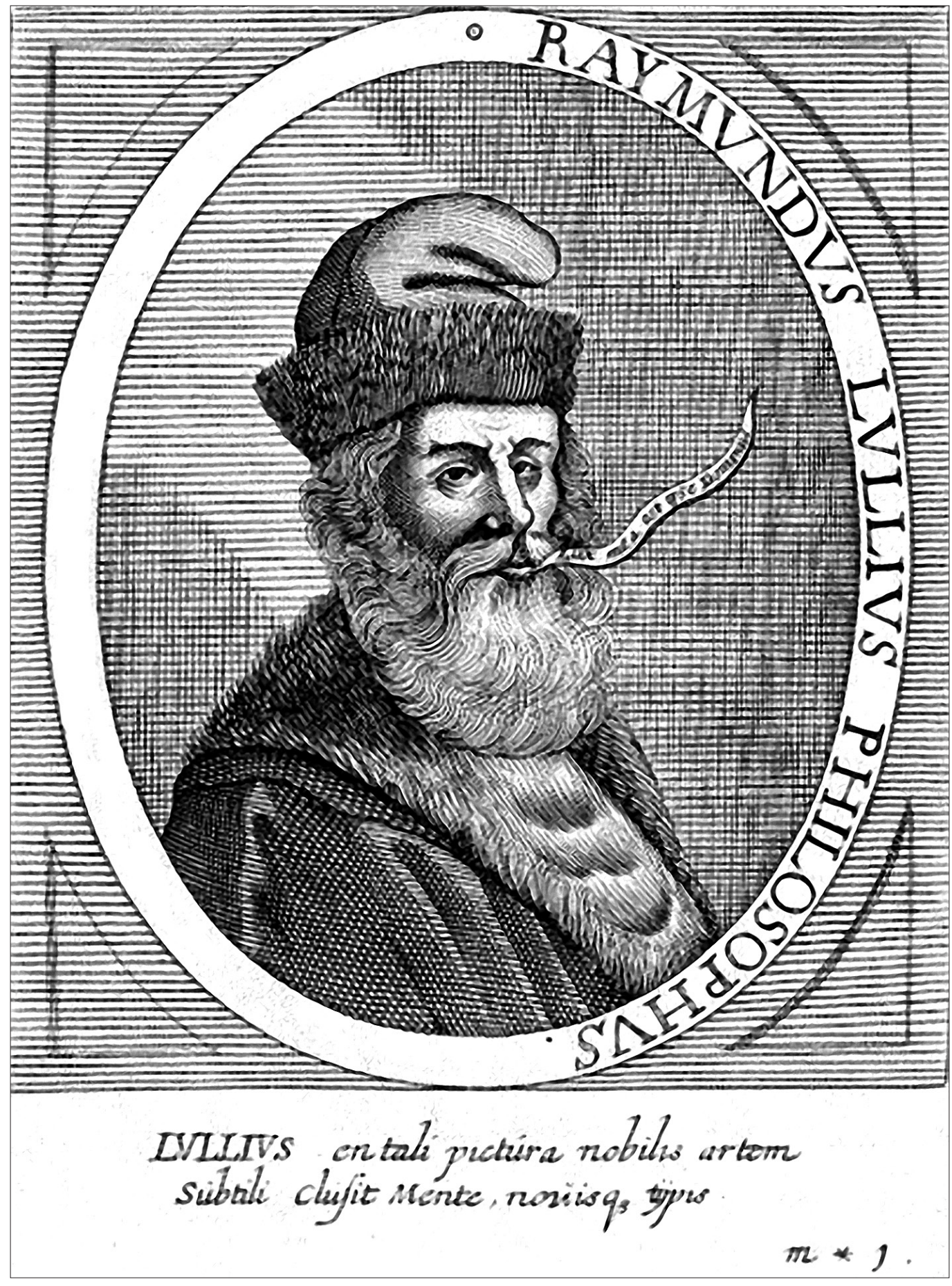

En fecha incierta entre diciembre de 1315 y marzo de 1316 moría, quizás en Túnez o de regreso a Mallorca, Ramón Llull, el filósofo nacido en Mallorca hacia 1232, autor polifacético que plasmó su técnica o Arte para convencer de la verdad de la fe en unas 260 obras, actualmente catalogadas y editadas. Para conmemorar el séptimo centenario de su muerte, en noviembre de 2015 se inició un conjunto de actos académicos y divulgativos alrededor de su figura. La sesión luliana propiciada por el X Congreso Internacional de la Sociedad Española de Emblemática celebrado en Palma en diciembre de 2015 constituyó una de las primeras aportaciones en la conmemoración de l'Any Llull. Se recogen aquí el estudio de Anthony Bonner, referente internacional en las investigaciones sobre la obra Llull -especialmente acerca de los fundamentos lógicos y matemáticos del Arte-, el de Miquela Sacarès, especialista única en la iconografía sobre Ramón Llull -que se desarrollará desde 1325 hasta nuestros días- y la introduccción general de Anna Serra, especialista en iconología e investigadora de las figuras que esquematizan el Arte. 


\title{
LA FORMA I LA LLETRA EN RAMON LLULL. UNA BREU INTRODUCCIÓ ALS ELEMENTS VISUALS EN L'OBRA LUL·LIANA
}

\author{
FORMS AND LETTERS IN RAMÓN LLULL. A BRIEF INTRODUCTION TO \\ VISUAL ELEMENTS IN LLULL'S WORKS
}

Anna Serra Zamora
Universitat Pompeu Fabra

No ha estat fins fa poc temps que s'ha posat el focus d'atenció en la gran riquesa de l'obra lul-liana pel que fa al llenguatge visual, un element que va tenir un ampli desenvolupament al llarg del lul·lisme del Renaixement i del Barroc, però també en l'art contemporani. D'entrada, en les figures lul-lianes es troben elements que requereixen una reflexió: l'ús de formes i de lletres, i, en definitiva, la construcció d'una diagramàtica sobre la qual encara avui cal aplicar una catalogació i una interpretació més enllà de desentrellar-ne l'aplicabilitat o funcionalitat en relació amb cada text, aspectes que l'investigador A. Bonner ha estudiat a bastament, junt amb A. Soler.

\section{VIDA, VISIÓ CONVERSIVA I IL·LUMINACIÓ COMPRENSIVA}

Ramon Llull va néixer a Mallorca el 1235, pocs anys després de la conquesta de Jaume I. A l'illa convivien cristians, jueus i musulmans, fet que, juntament amb les seves vivències espirituals, va alimentar en l'autor la voluntat d'establir un sistema de coneixement integrador, que posés acord en els punts bàsics de les tres religions del Llibre, i a partir d'aquí es pogués convertir els infidels, és a dir, els no creients o els creients no cristians. Proposà, com a punts en comú, les dignitats de Déu: setze en les primeres obres, i, finalment, nou: bonesa, grandesa, eternitat, poder, saviesa, voluntat, virtut, veritat, glòria. Això ha estat motiu de considerar-lo el pare del diàleg interreligiós, en un món, el seu, de croades, a què ell anteposava l'argumentació. Aquest intent de síntesi, de simplificació a elements bàsics, 
és probablement un dels motius principals pels quals Llull recorre a les figures, és a dir, formes -majoritàriament geomètriques- acompanyades per lletres, sobre les quals plantejar qüestions, trobar solucions a les qüestions plantejades, i, en definitiva, trobar el consens de raons, i amb ell, el consens de creences, fent real la conjunció entre fe (veritat revelada) i raó (lògica demostrativa); un consens que conclouria amb la conversió irrevocable al cristianisme.

Ramon va créixer en un ambient de cort, cultivava la poesia trobadoresca, va crear una família i gestionava el seu patrimoni. Una vida que va canviar quan se li va aparèixer en visions Crist crucificat fins a cinc vegades, una experiència visionària que ha estat anomenada conversió a la penitència i que el va menar a convertir els infidels, redactar el millor llibre del món contra els errors dels infidels i fundar monestirs que preparessin missioners per convertir. En aquest punt de la seva vida, a l'entorn de 1263, va abandonar l'estil de vida anterior i va iniciar un període de formació autodidacta que el va portar a l'eclosió de la seva obra, amb més de 240 títols, de temàtica apologètica, teològica, filosòfica, artística, mèdica, jurídica, lògica, mística, astronòmica, didàctica..., escrits en català, llatí i àrab. Per difondre els seus textos, Llull es va moure pels àmbits acadèmics de París, els monàrquics de Montpeller, els religiosos de Roma i els musulmans del nord d'Àfrica, amb una gran emprenedoria intel-lectual. Tots aquests episodis de la seva vida queden plasmats en la biografia que va dictar ell mateix cap a 1311 als deixebles que tenia a París, la Vida coetània, de la qual es conserva una edició il-luminada preciosa amb dotze miniatures, empresa per Thomas Le Myésier (Breviculum, 1325), que han establert les bases de les imatges devocionals posteriors, estudiades per Batllori, Hillgarth, Hasler, Sebastián, Cantarellas i Sacarès.

Les dues primeres obres de Ramon Llull són la Lògica del Gatzell (1271), un comentari en vers de la lògica àrab, desproveït de figures, i el Llibre de contemplació (1274), ric en figures, per contra. La tradició d'estudis lul-lístics ha anomenat preartística la primera etapa de producció, fins a 1274, és a dir, anterior a l'ars, que és el gran mètode filosòfic, teològic i icònic del pensament lul·lià, sorgit de l'experiència d'il-luminació a Randa, entesa com una il·lustració, revelació o comprensió integral. Es podria parlar, doncs, d'un corpus visual preartístic, constituït per les figures del Llibre de contemplació, que pretenen estructurar tots els elements del cosmos per mitjà, fonamentalment, d'arbres de coneixement de tipus porfirià i una llarga col-lecció de figures inserides en el text. Es percep, doncs, des de l'inici de la seva producció, una necessitat explícita d'expressar per via de les formes sensuals les seves estructures intel-lectuals, és a dir, de fer visibles les estructures del coneixement.

Però, amb la il·lustració de Randa, se li van comunicar "mode i forma», és a dir, una abstracció visual vinculada a un mètode, l'ars, que desenvoluparà primer amb principis múltiples de quatre (art quaternària), i, a partir de 1290 (Ars inventiva veritatis), més simplificadament, amb múltiples de tres (art ternària). El seu deixeble, Thomas Le Myésier, ens dóna la seva versió a la miniatura 4 del Breviculum, posant veu al seu mestre: «Oh Déu, que per gràcia teva has volgut mostrar-me avui els principis substancials i accidentals de totes les coses, i m'has ensenyat a fer-ne dues figures!». Es refereix a la figura A, de les dignitats de Déu (una sola essència, sense composició ni accidents per separat) [fig. 1], i, o bé la taula, o la figura S (de l'ànima racional) o la T (de principis i significats). És a dir, la il·lustració de Randa es pot entendre com una visió figural, i és a partir de llavors - tot i que al Llibre de contemplació ja hi ha figures- que Llull desenvolupa tota una diagramàtica pròpia i original, des de l'Ars compendiosa inveniendi veritatem (1274, amb sis figures: A S T X Y Z i les respectives taules) fins a l'Ars generalis ultima i l'Art breu (1308), en què el nombre de figures del seu sistema queda reduït a quatre, fet que demostra que l'autor polia el seu pensament i volia fer-lo més concís. 


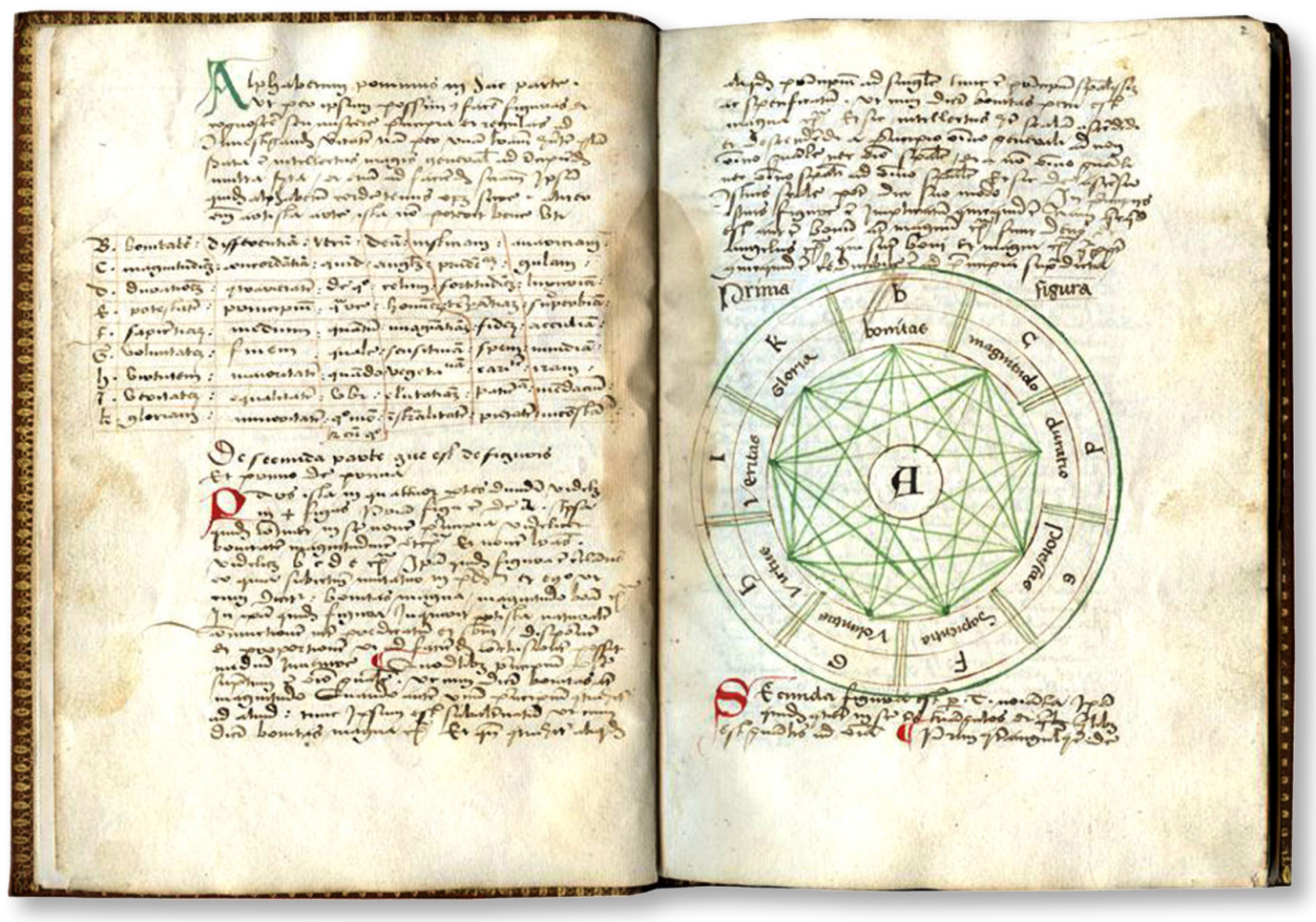

Fig. 1. Ramon Llull, Ars brevis, manuscrit en paper, Sud d'Holanda ca. 1490-1550.

\section{LA DIAGRAMÀTICA LUL·LIANA}

Per diagramàtica entenem el conjunt de figures de les obres de Llull que representen, relacionalment, conceptes: no són imatges decoratives, no són il·lustracions a un contingut sinó que són el contingut mateix plasmat en una imatge que fa visible, articula, genera i reprodueix el mecanisme mateix del raonament, són figures de pensament, funcionals. La producció icònica de Llull inclou arbres, cercles fixos, rodes giratòries (volvelles), taules (amb lletres, amb punts), figures geomètriques, així com formes més evolucionades producte del mateix autor o dels copistes, com rodes arbre, arbres creu, creus escala, mans mnemòniques, etc., amb una abundant variació en els manuscrits i edicions impreses, de les quals una de les més importants és la d'Ivo Salzinger (s. XVIII), la qual, al seu torn, conté una imatge de naturalesa emblemàtica al frontispici, que encara requereix una anàlisi exhaustiva [fig. 2].

Els diagrames lul-lians són recursos integrats al text i interactius amb al text, i que, com aquest, articulen raons necessàries i esdevenen eines heurístiques o inventives, és a dir, atrobadores de la veritat, amb una voluntat omnicomprensiva i harmonitzadora. No són formes visionàries però sí vinculades a una revelació i ofereixen una clavis universalis, una via de comprensió íntegra del coneixement humà i dels elements del món, inclòs, i principalment, Déu. Els diagrames sovint expressen la relació combinatòria entre un conjunt tancat d'elements, amb mecanismes com la tabulació o la rotació, és a dir, rodes que giren i que 
constitueixen imatges tàctils i cinètiques, com veritables instruments que demanen ser activats. I com que són figures que porten a la veritat teològica, i a través de les quals s'exercita el coneixement, es tracta d'elements meditatius o devocionals, complementaris a les artes praedicandi, i que podríem considerar, en un cert sentit, figures d'oració. Són instruments de comprensió, de meditació i de conversió.

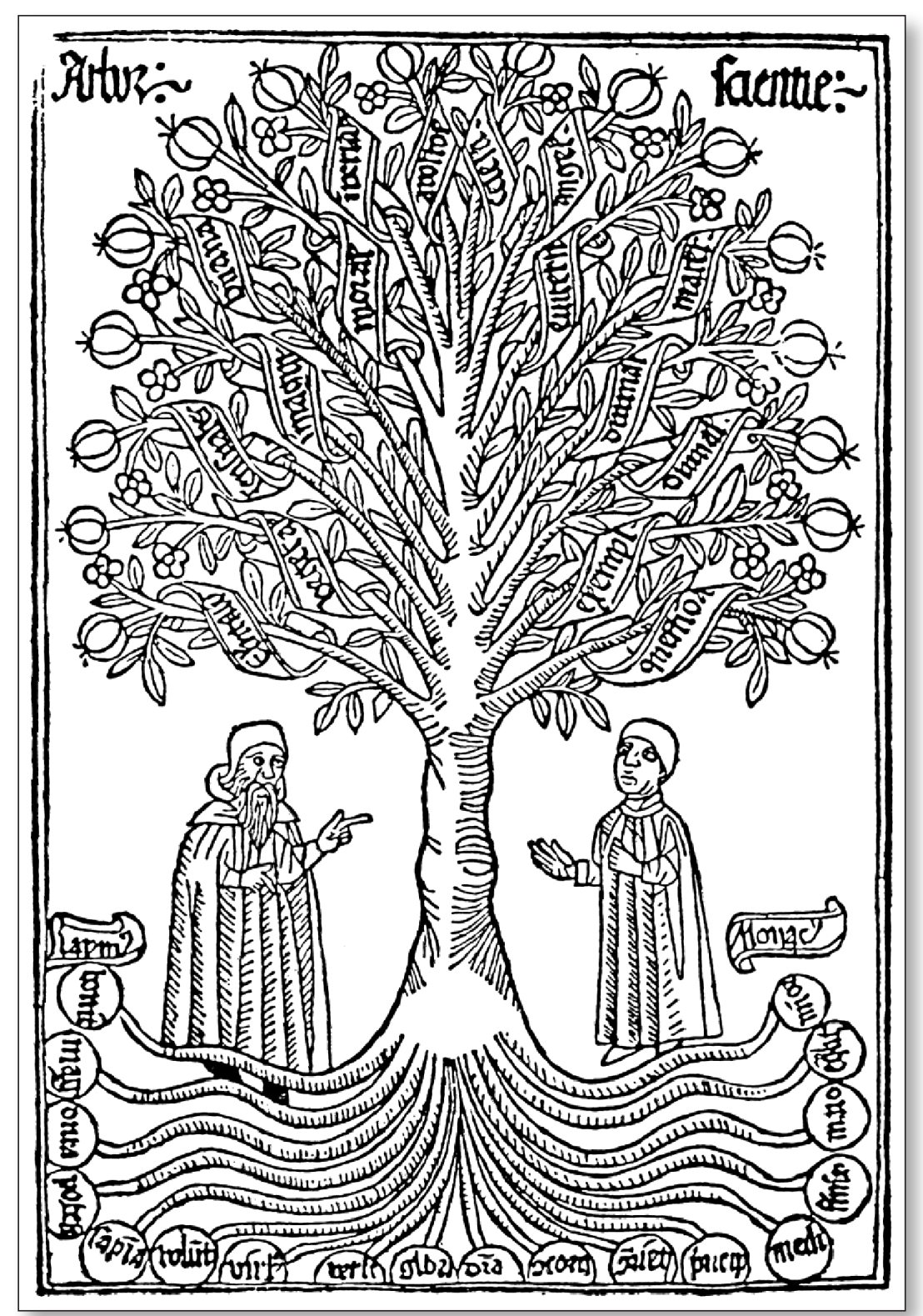

Fig. 2. Diagrama Arbor scientiae. 
Els diagrames permeten una mecanització del coneixement, i, per això, es podrien considerar eines computacionals, però el càlcul combinatori de Llull no usa xifres sinó lletres, per això la noció d'abecedari és molt important. Les imatges dels manuscrits lul-lians combinen paraules i lletres, rarament hi ha sintagmes o frases. Per tant, pren relleu l'ús de la lletra sola, és a dir, un alfabet simbòlic, atès que a cada lletra li correspon un concepte (dignitats de Déu, facultats de l'ànima, qüestions...), que queda indicat en els textos corresponents, però la combinatòria li dóna una certa elasticitat de significat, ja que pot variar segons el context. J. E. Rubio ha parat atenció a aquest recurs d'economia informativa basat en l'abreviació del contingut per manipular-lo més fàcilment a través del mecanisme de combinació en el context d'un llenguatge mental, d'una significació intel-lectual i moral. Així mateix, l'alfabet aporta l'avantatge de poder ser emprat per persones de diferents idiomes, com un codi transcultural. D'alguna manera, la lletra és l'ànima de la figura. A partir de combinar les lletres, doncs, es combinen els conceptes i es formen frases o argumentacions que cal saber construir, articular, bastir: això és el que fa l'artista. Es requereix conèixer una gramàtica lògica per articular subjectes i predicats de manera concordant. Per això, es podria dir que la diagramàtica neix d'una necessitat gramatical o logicogramatical.

\section{LA IMATGE COM A VIA EPISTEMOLÒGICA}

Llull entén la imatge com el vincle entre el sensual i l'intel-lectual, dos mons que sempre vol conciliar, i que actualment podríem considerar com una interfície, aquest espai connectiu dels sentits i la ment. De tota manera, les figures lul-lianes no solen ser d'estil naturalista, llevat d'alguns arbres, sinó fonamentalment geomètric, abstracte. No són figures fetes per al plaer dels sentits, però els sentits són la via d'accés per a la comprensió i la devoció.

A la ja esmentada Ars compendiosa inveniendi veritatem, Llull proposa cinc figures, la funció de les quals, diu, és trobar la veritat de manera sintètica, contemplar i conèixer Déu i vivificar les virtuts i els vicis. Així que les figures lul-lianes tenen un sentit no només epistemològic i teològic sinó també moral, ontològic. No es tracta de figures simbòliques, sinó d'un mètode, un instrument, un aparell lògic, figures mecàniques, $i$, per aquest motiu, podríem dir que són figures científiques, en el sentit que les imatges són màquines del pensar, i, per tant, del conèixer. Això implica que es visualitza el saber (part sensitiva) i que alhora se'l fa operatiu a través de la imatge mateixa, que activa el pensament (part intel·lectiva) -és l'àmbit de la imatge mental. Aquesta duplicitat fa que les figures lul-lianes siguin molt aptes per a la didàctica en l'àmbit de la predicació, ja que combinen una part més intuïtiva amb una d'altra més enigmàtica-conceptual que requereix d'una tasca de pensar i de memoritzar.

Per tant, les figures tenen una funció instrumental, com a objectes que reflecteixen espais de la ment. Els llocs de la ment, o, més pròpiament, els processos lògics que generen les combinacions de lletres estan representats gràficament amb línies connectores dins dels cercles o les cambres de les taules. Fer girar la roda, crear combinacions, és crear llocs teòrics, sentències, frases, una narració lògica. Les rodes lul-lianes són imagines agentes, en el sentit que activar-les -manualment i mentalment- suposa l'activació del pensament, del qual són una visualització; la imatge fa visibles els actes de l'enteniment. És imprescindible la noció de moviment, d'imatge en moviment, de reflexió en moviment, entre l'exercici lúdic i l'exercici lògic. Llull havia usat el mecanisme de la rotació a l'Ars notatoria (1274), basada en una taula d'equivalències conceptuals, en la qual una mateixa lletra era usada

IMAGO, NÚM. 8, 2016, I24-130 
en quatre posicions: és a dir, es feia una rotació de la lletra com a signe (per exemple, les quatre posicions de la lletra $k$ significaven els quatre elements). Tot i que Llull creia que les figures només s'adreçaven a persones no formades en l'art (almenys així ho diu al Llibre de contemplació), el pensament té necessitat del sensual, de la forma, de l'objecte visual, ja que l'intel-lecte treballa amb imatges, i, de fet, el pensament lul-lià és un pensament relacional en imatges. L'objectiu final seria abandonar els recursos visuals i convertir el mecanisme après en una geometria de la ment, autònoma. 